\title{
Development of "Press Tap" Hand Washing Technology: Design, Construction and Operational Aspects
}

\author{
Ababu T. Tiruneh ${ }^{1}$, William N. Ndlela ${ }^{1}$, Jonna Heikkilä ${ }^{2}$ \\ ${ }^{1}$ Department of Environmental Health Science, University of Swaziland, Mbabane, Swaziland \\ ${ }^{2}$ Faculty of Technology, Turku University of Applied Sciences, Turku, Finland
}

Email address:

atiruneh@uniswa.sz (A. T. Tiruneh),wndlela@uniswa.sz (W. N. Ndlela), jonna.heikkila@turkuamk.fi (J. Heikkilä)

To cite this article:

Ababu T. Tiruneh, William N. Ndlela, Jonna Heikkilä. Development of "Press Tap" Hand Washing Technology: Design, Construction and Operational Aspects. International Journal of Science, Technology and Society. Vol. 4, No. 3, 2016, pp. 48-56.

doi: $10.11648 /$ j.jists.20160403.12

Received: May 22, 2016; Accepted: May 30, 2016; Published: June 13, 2016

\begin{abstract}
Achieving hygiene through hand washing is an important intervention in interrupting the cycle of transmission of communicable diseases. A hand washing facility named "Press Tap" has been developed and was successfully tested in different user environments. The hand washing device - which is simple and low cost - works on a foot pressing mechanism and integrates the usage of soaps using the same mechanism. This paper presents the conceptual development of the Press Tap including the governing hydraulic equations of flow that form the theoretical basis for the design of the hand washing facility. The paper also gives the construction features of the different components as well as useful operation aspects that were realized during the pilot trials of the device in different user environments.
\end{abstract}

Keywords: Hygiene, Hand Washing, Tippy Tap, Water Supply, Sanitation, Toilets, Public Health, Infectious Diseases

\section{Introduction}

Hygiene is considered as a pillar of development of health and as an easy, effective, and affordable "do-it-yourself vaccine" that prevents infections and saves lives. Infection prevention is at the heart of strengthening health-care systems while hand hygiene is core to all interventions. The simple action of washing hands with soap can interrupt the transmission of both diarrhea and pneumonia, the two biggest causes of deaths of children under five [1]. Studies have found that hand washing with soap reduced the risk of diarrheal diseases by $48 \%$ and the risk of respiratory diseases by $21 \%$ ([2], [3]). According to the Global PublicPrivate Partnership for Hand washing [4], hand washing with soap was shown to reduce diarrheal disease, intestinal helminthes infection, under nutrition, stunting, maternal mortality, hand foot and mouth disease, hepatitis A, schistosomiasis, foodborne infections and water supply contamination. Improved hand washing practices have also been shown to lead to small improvements in the growth in children under five years of age.

The need for appropriate hand washing device is strong where traditional hand washing devices such as running taps or wash basins are not available. Communities in resource scarce areas often find it difficult to practice hand washing in hygienic manner after using toilets or while doing activities such as food preparation that need hand cleaning if facilities for hand washing are not available at convenient location [5]. The adoption of enabling hand washing devices such as the tippy tap is thus appropriate in such situations as hand washing practice in infrastructure restricted settings remain low [6].

Hand washing devices such as the tippy tap are also water saving devices requiring a volume only of about $40 \mathrm{~mL}-200$ $\mathrm{mL}$ per hand wash compared to traditional hand washing using for example a beaker which may require the use of up to $500 \mathrm{~mL}$ of water per hand wash. Among the factors influencing hand washing behavior - namely, opportunity, ability and motivation - the availability of water and soap are considered as opportunity factors that can determine hand washing behaviors. In this regard, the use of water saving appropriate hand washing devices can improve the hand washing behavior among communities [7]. A number of studies of hand washing behavior also revealed that access/availability of water and soap at convenient and 
designated place as being strongly correlated with improvement in hand washing practice ([8]; [9]; [10]; [11] and [12]). The provision of simple hand washing device such as the tippy tap around the household and the promotion of hand washing practice have reportedly improved hand washing practices considerably [13].

Hand washing devices that are needed in resource restricted areas should be simple technologies with few moving parts. They should be self-standing and requiring no external energy inputs such as fuel or electricity. They should be constructed of locally available material where the parts and supplies need to be made locally [6]. Several technological designs are available for use as hand washing devices with varying degree of acceptability in different user environments. Examples of such hand washing technologies include: The tippy tap, a drum with tap and container for soap, a bottle with valve cap, soapy water bottle with pump, leaky water bottle and kitchen bucket with or without tap.

The suitability for use of such simple hand washing devices is, however, variable. For example the bottle with valve cap requires one hand for opening the cap while the other hand receives the water. Users reportedly found this difficult especially for younger members of families. There are also disgust factors where users did not like touching a bottle cap and soap after another user coming from toilet did the same ([14]; [5]). Some devices such as the drum with a tap wastes a lot of water and can leave the ground muddy. Children may also leave the taps open leading to wastage of water and muddying of the receiving ground. Location of the hand washing device also influences hand washing practice as devices located near toilets may prove to be too far for users wanting to wash hand in relation to food preparation. Hand washing devices with small containers such as the bottle are reportedly inadequate as they demand having to be filled frequently particularly when they are provided as common hand washing device for multiple users. There is also a problem of sharing responsibility that comes with the need to fill containers frequently among users who may not cooperate on equal level. Some hand washing devices such as buckets and solid bar soaps can be easily stolen where users are reportedly forced to store them away at night for fear of theft. Devices with hard-to-replace parts such as valves that are provided to bottles or drums may be unsuitable as it may be difficult to replace them once they got broken or possibly got stolen.

On gender aspects, women are reported to be more relevant to hand washing issues compared to men as they spend more time at home using hand washing devices and are often left with the responsibility of having to teach young members of the family on the use of hand washing [15].

Devices that make soap available are also important where soaps are supplied commonly either as solid bars, powders or in solution. While the solid bar can be conveniently suspended or simply placed, provision of powder and liquid soaps in a user friendly and hygienic manner can be difficult [16].
The tippy tap is a well-known appropriate technology device for hand washing and is a suitable device for improving hand washing behavior. Tippy taps made of local materials have been promoted in communities lacking access to running water for over 20 years [17]. Tippy taps can be constructed of low cost, locally available materials and they conserve water. The tippy tap uses on average of 40- $200 \mathrm{~mL}$ per hand wash [18]. Surveys of suitability of simple hand washing devices such as the Tippy tap also revealed that users prefer such simple devices for a number of reasons. These reasons include: Ease of use, convenient location of the devices where they are needed for hand washing, ability to save water, taking less time to wash hands, being cheap, presence of soap, convenience of use by all members of a family and providing clean water and preventing pollution [13].

The tippy tap has, however, a number of disadvantages. The components such as jerry can, strings and posts need to be replaced. Plastic storage tanks particularly degrade in the sun leading to cracks and leaks. Soaps are also seen to be eaten by goats or stolen at night [19].

Sustainability of operation of hand washing facilities is critical if intended benefits of hand washing are to be achieved over the longer term. However, some positive assessment of the infrastructural sustainability of hand washing devices may have been overstated [4]. The period of monitoring and evaluation for testing the sustainability of hand washing devices tends to be too short often not exceeding one year. Examples of such evaluations are hand washing facilities installed in health care facilities in Kenya which were evaluated over a 4 month period ([20]; [21]; [22]), Tippy taps constructed in rural areas in Ethiopia were evaluated over 3 months period while those built for households in Zimbabwe were evaluated over a one year period ([23]; [24]). There are reports of abuses of hand washing devices such as the tippy tap where children play with it as a toy, convert it to a see-saw or just decide to break it [13]. Children are also observed to let the water flow out of the container until the device runs dry. According to Luby et al [10], hand washing interventions tend to be abandoned or become ineffective after 2 years of their introduction and that monitoring and evaluation of the use of hand washing facilities is necessary to ensure their sustainable use.

The provision of simple and appropriate hand washing facilities should be preceded as well as followed by proper education and awareness raising on hand washing. It is generally believed that hand washing practices tend to be over reported some which are caused by the techniques used in observing such practice and the limited period of observation following installation of hand washing facilities when the practices of hand washing are induced by the project [25].

A simple "Press Tap" hand washing facility was developed by the authors of this research paper at the University of Swaziland and is presented in this paper. The hand washing device operates by a gentle pressing of foot lever located on 
the ground. The action of the foot lever transmits force through attached ropes that results in pressing of the container holding water through two wooden flaps. The device is hygienic as it is operated by foot and does not involve using hands that may be contaminated before the hand washing. The innovative device has been initially tested as group hand washing facility at the Mangwaneni Children care point in Mbabane, at the New Hebron School and at the Church of Jesus Christ in Mnyamatsini. The initial pilot trials have produced promising results prompting the need for more development in various user environments. The sections below discuss the conceptual development, construction and operational feature of this newly developed hand washing facility.

\section{Materials and Methods}

The development of this innovative hand washing facility passed through stages of conceptual development, theoretical design, construction and operation stages. The conceptual development, design, construction and operation aspects are covered in the results and discussion section. The conceptual development of the Press Tap is based up on equilibrium created on a container of water with hole at the bottom by the forces acting on the water column passing through the hole. A mechanical pressing of the container disturbs the equilibrium causing water flow through the bottom hole of the container. The technical arrangement for transmitting force from the foot lever to the container through ropes and wooden flaps is explained. The design is based on development of the governing equilibrium equation involving forces of gravity, internal and external air pressure, weight of water and surface tension forces. The volume of loss of water as a percentage of the container volume is developed and presented based on the developed equilibrium equations. The effect of altitude on the volume loss is computed according to the variation of prevailing air pressure with altitude. The construction and operational aspects of the press tap hand washing facility are also explained.

\section{Results and discussion}

\subsection{Conceptual Development}

The Press tap facility consists of a foot lever that is located on the ground. The foot lever is connected to two ropes that are extended to the two wooden flaps that are provided to the left and right of a water holding container. The schematic of the press tap hand washing facility is shown in Figure 1 below. The wooden flaps are used to press the water holding container. The pressing of the water holding container forces water to be squeezed out of the container. The water holding container ranges in volume between 1 liter and six liters and is normally hanged from a frame at the top.

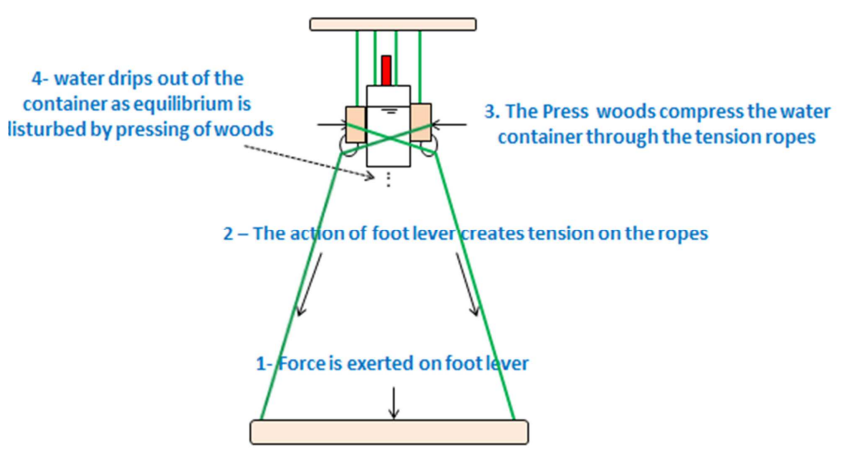

Figure 1. Schematic diagram of the Press Tap hand washing facility.

Pressing of the foot lever exerts a downward force which in turn forces the connected ropes to be subjected to tensile forces. The development of tension in the ropes in turn forces the wooden flaps provided to the right and left of the water holding container to be drawn towards the container. This action of the wooden flaps presses the water holding container. The pressing of the water holding container disturbs the equilibrium that retains water in the container. The disturbance forces water to drop out through a small hole provided at the bottom center of the water holding container. When the foot is disengaged from the foot lever after use, the wooden flaps, rope and water holding container revert to their original position.

The action of the foot lever is gentle requiring little force to squeeze water out of the container. Therefore, the device is easy to use and can be used by children as well. The device is also hygienic as hand is not being used to open or close taps as instead the device operates by foot. The device is simple to construct and can be constructed from locally available materials. It is also a low cost device as the component materials can be afforded at lower cost.

\subsection{Development of Equations Governing Water Flow and Stoppage}

A complete development of the governing equations of the Press tap hand washing facility is provided below. As shown in Figure 2, the forces acting on the water held inside the container include gravity force, air pressure on both the inside and outside of the container and surface tension force at the bottom hole between the water and the water holding container surface.

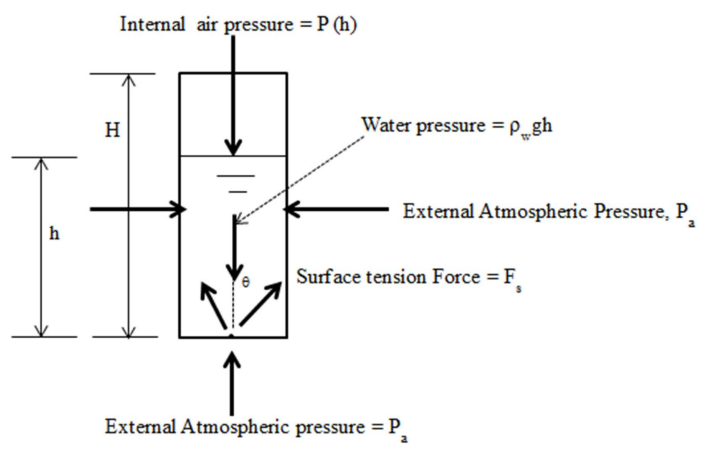

Figure 2. Forces acting on the water held inside the container of the Press Tap hand washing device. 
Considering a vertical column of water extending from the bottom hole upwards to the height of flow stoppage $h$, the equilibrium of forces in the vertical direction leading to flow stoppage is written as follows:

$$
\sum F_{y}=\left(P_{h}+\rho_{w} g h-P_{a}\right) \frac{\pi d^{2}}{4}-\pi d \sigma \operatorname{Cos}(\theta)=0
$$

Where:

$\mathrm{P}_{\mathrm{h}}=$ the internal pressure acting on the air water interface inside the container

$\rho_{\mathrm{w}}=$ Density of water $=1000 \mathrm{~kg} / \mathrm{m}^{3}$

$\mathrm{g}=$ Acceleration due to gravity $=9.81 \mathrm{~m} / \mathrm{s}^{2}$

$\mathrm{h}=$ The height of water column when flow from the container stops.

$\mathrm{Pa}=$ atmospheric pressure (variable) assumed initially $1.01 * 10^{5} \mathrm{~N} / \mathrm{m}^{2}$

$\mathrm{d}=$ Diameter of the hole at the bottom center of the container (taken as $2 \mathrm{~mm}$ )

$\sigma=$ Surface tension of water $=0.073 \mathrm{~N} / \mathrm{m}$

$\theta=$ Contact angle of water with polyethylene container taken as $63^{\circ}$

The following assumptions are held:

- Ideal Gas Laws are applicable

- The compression of the container volume caused by external pressure exerted by the atmospheric pressure on the outer surface of the container is negligible.

- Release of air from the water as the pressure inside the container reduces is negligible.

Assumptions 2 and 3 are not always valid and can lead to significant error in the calculation particularly for large size container and containers that are easily compressed because of the difference between internal and external pressure acting on the container walls.
Returning to the equilibrium forces equation (1) above

$$
\begin{gathered}
\sum F_{y}=\left(P_{h}+\rho_{w} g h-P_{a}\right) \frac{\pi d^{2}}{4}-\pi d \sigma \operatorname{Cos}(\theta)=0 \\
P_{h}=P_{a}-\rho_{w} g h+\frac{4 \sigma \cos (\theta)}{d}
\end{gathered}
$$

From the ideal Gas Laws for constant temperature conditions and assuming the initial and final volume of air space in the container were $\mathrm{V}_{0}$ and $\mathrm{V}_{\mathrm{h}}$ respectively,

$$
P_{a} V_{0}=P_{h} V_{h}
$$

From which;

$$
\frac{P_{a}}{P_{h}}=\frac{V_{h}}{V_{0}}
$$

The fraction of volume change of air space in the container is calculated as:

$$
\frac{\Delta V}{V_{0}}=\frac{V_{h}-V_{0}}{V_{0}}=\frac{V_{h}}{V_{0}}-1=\frac{P_{a}}{P_{h}}-1
$$

Substituting the $\mathrm{P}_{\mathrm{h}}$ value of equation (2) into equation (3) and rearranging gives:

$$
\frac{\Delta V}{V_{0}}=\frac{\rho_{w} g h-\frac{4 \sigma \cos (\theta)}{d}}{P_{a}-\rho_{w} g h+\frac{4 \sigma \operatorname{Cos}(\theta)}{d}}
$$

Using sea level atmospheric pressure $\left(1.01 * 10^{5} \mathrm{~N} / \mathrm{m}^{2}\right)$ and assuming that the initial height of the container is equal to 30 $\mathrm{cm}$, the angle of contact of water and polyethylene bottle is $63^{\circ}$ and taking the surface tension of water as $0.073 \mathrm{~N} / \mathrm{m}$, yields the following result:

$$
\frac{\Delta V}{V_{0}}=\frac{\left(1000 \mathrm{~kg} / \mathrm{m}^{3}\right) * 9.81 \frac{\mathrm{m}}{\mathrm{s}^{2}} * 0.3 \mathrm{~m}-\frac{4 * 0.073 \mathrm{~N} / \mathrm{m} \operatorname{Cos}\left(63^{0}\right)}{2 * 10^{-3} \mathrm{~m}}}{1.01 * 10^{5} \mathrm{~N} / \mathrm{m}^{2}-\left(1000 \mathrm{~kg} / \mathrm{m}^{3}\right) * 9.81 \frac{\mathrm{m}}{\mathrm{s}^{2}} * 0.3 \mathrm{~m}+\frac{4 * 0.073 \mathrm{~N} / \mathrm{m} \operatorname{Cos}\left(63^{0}\right)}{2 * 10^{-3} \mathrm{~m}}}=0.03
$$

Table 1. Variation of percentage volume loss of water with container height.

\begin{tabular}{lllll}
\hline $\begin{array}{l}\text { Container } \\
\text { height }\end{array}$ & $\begin{array}{l}\text { Altitude above } \\
\text { Mean Sea Level }\end{array}$ & $\begin{array}{l}\text { Atmospheric } \\
\text { pressure }\end{array}$ & $\begin{array}{l}\text { volume } \\
\text { change }\end{array}$ & $\begin{array}{l}\text { Volume } \\
\text { change (\%) }\end{array}$ \\
\hline $\mathbf{( c m )}$ & $\mathbf{( m )}$ & $\mathbf{( N / \mathbf { m } ^ { 2 } )}$ & $\mathbf{( V / \mathbf { V } _ { \mathbf { 0 } } )}$ & \\
\hline 10 & 0 & 101000 & 0.0091 & 0.9 \\
15 & 0 & 101000 & 0.0141 & 1.4 \\
20 & 0 & 101000 & 0.0191 & 1.9 \\
25 & 0 & 101000 & 0.0241 & 2.4 \\
30 & 0 & 101000 & 0.0293 & 2.9 \\
35 & 0 & 101000 & 0.0344 & 3.4 \\
40 & 0 & 101000 & 0.0397 & 4.0 \\
45 & 0 & 101000 & 0.0449 & 4.5 \\
50 & 0 & 101000 & 0.0503 & 5.0 \\
100 & 0 & 101000 & 0.1067 & 10.7 \\
200 & 0 & 101000 & 0.2400 & 24.0 \\
400 & 0 & 101000 & 0.6336 & 63.4 \\
800 & 0 & 101000 & 3.4717 & 347.2 \\
1000 & 0 & 101000 & 33.0493 & 3304.9 \\
\hline
\end{tabular}

It is apparent that the volume change is only $3 \%$ and for small containers the water flow may not even be noticeable. The calculation is repeated for different heights of containers and different atmospheric pressure varying with altitude and the results are tabulated below.

In actual case the volume change to stoppage of flow is larger because of lack of validity of the assumptions stated above. In fact, experiment with large size container (25 liters) shows that water flow does not stop easily and continues to flow almost half way before it stops. The possible explanations for this anomaly are:

- Compression of the container by external atmospheric pressure and resulting added pressure

- Large amount of dissolved air released from the water may increase the internal pressure. 


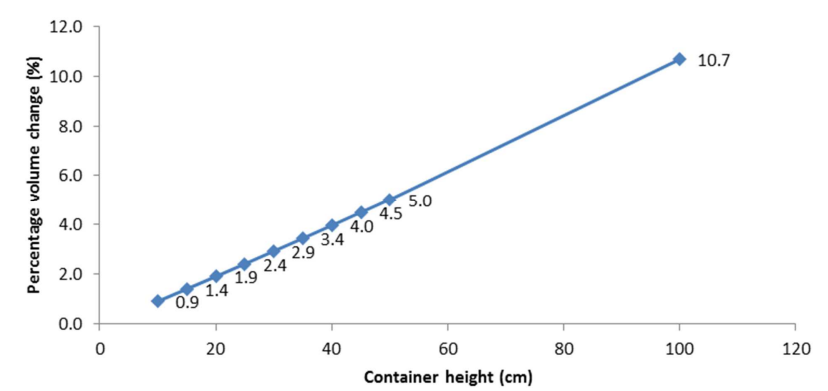

Figure 3. The initial water loss as percentage of the total volume of the container depending on container height.

Table 2. Variation of percentage volume loss of water with altitude.

\begin{tabular}{lll|ll}
\hline $\begin{array}{l}\text { Container } \\
\text { height }\end{array}$ & Altitude & $\begin{array}{l}\text { Atmospheric } \\
\text { pressure }\end{array}$ & $\begin{array}{l}\text { volume } \\
\text { change }\end{array}$ & $\begin{array}{l}\text { Volume } \\
\text { change (\%) }\end{array}$ \\
\hline$(\mathrm{cm})$ & $(\mathrm{m})$ & $\left(\mathrm{N} / \mathrm{m}^{2}\right)$ & $\left(\mathrm{V} / \mathrm{V}_{0}\right)$ & \\
30 & 0 & 101000 & 0.0293 & 2.9 \\
30 & 450 & 96000 & 0.0308 & 3.1 \\
30 & 1000 & 89100 & 0.0333 & 3.3 \\
30 & 2100 & 78200 & 0.03819 & 3.8 \\
30 & 3000 & 69700 & 0.0430 & 4.3 \\
30 & 6000 & 46600 & 0.0657 & 6.6 \\
30 & 10000 & 23800 & 0.1374 & 13.7 \\
30 & 20000 & 5600 & 1.0563 & 105.6 \\
\hline
\end{tabular}

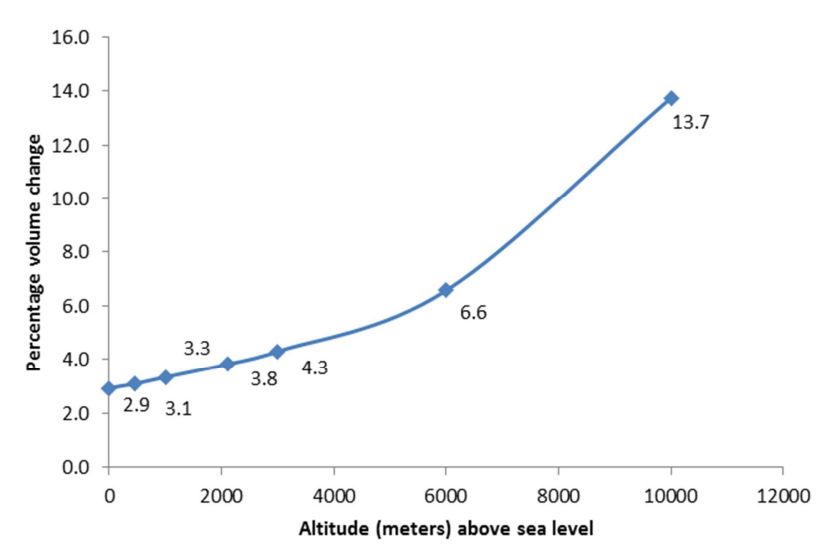

Figure 4. Variation of percentage volume change with altitude prior to attaining equilibrium.

\subsection{Construction of the Press Tap Hand Washing Facility}

Figures 5-11 illustrate the construction of the different components of the Press tap hand washing facility. The construction of components of the Press Tap hand washing facility can be accomplished with the use of locally available materials. As shown in Figure 5, the component materials of the Press Tap hand washing facility include: The wooden supporting frame from which the water holding containers are hanged, wooden flaps that are provided to the left and right of the water holding container, water holding container, foot lever provided at the bottom, vertical rods for securing the position of the foot lever and ropes for connecting the foot lever with the wooden flaps and suspending the water holding container from the supporting frame. In addition provision for soaps can be provided as will be explained later.

The foot lever can be built form any wood material that is strong enough to handle the exerted force of the foot. The size of the foot lever can be reduced to $50 \mathrm{~cm}$ length and $10 \mathrm{~cm}$ width as shown in Figure 6 in order to accommodate a number of hand washing facilities in parallel in a given location.

There are four ropes that connect the foot lever with the wooden flaps that are located to the right and left of the water holding container (Figure 6). The ropes are tied to the foot lever through two holes drilled at the front right and left ends of the foot lever. It is necessary to position the foot lever so that it is not to near to the position of the dripping water which will wet the feet. It should not also be located too far away which makes it difficult or the hand to reach the dripping water while the foot is pressing the foot lever. It is also necessary to secure the position of the foot lever as shown in Figure 7 using vertically driven wood pegs in order to discourage and restrain movement and possible dislocation of the foot lever from its desired position.

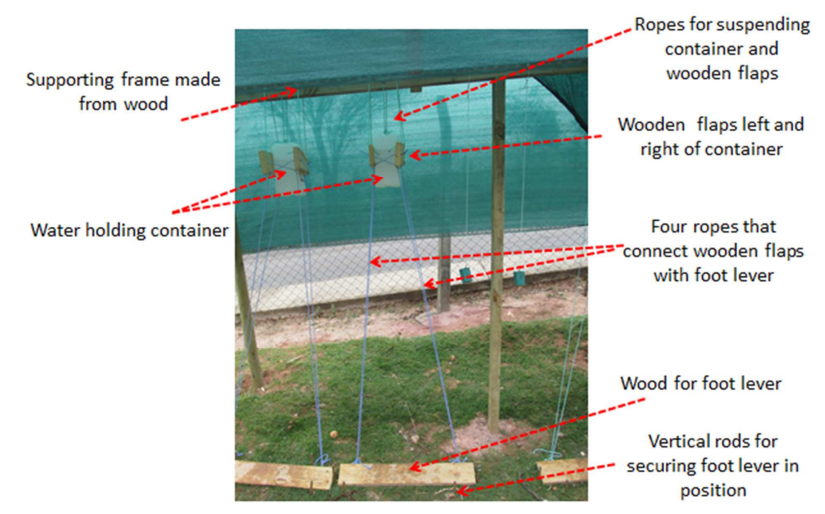

Figure 5. Components of the Press tap hand washing and the materials from which they are constructed.

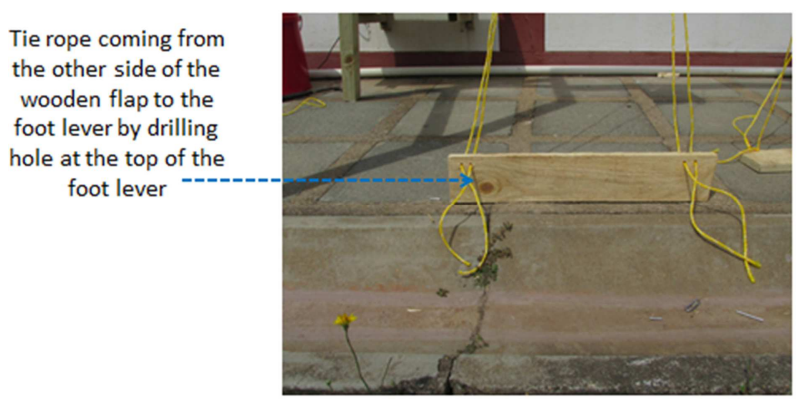

Figure 6. Construction foot lever with tension ropes for transmitting force.

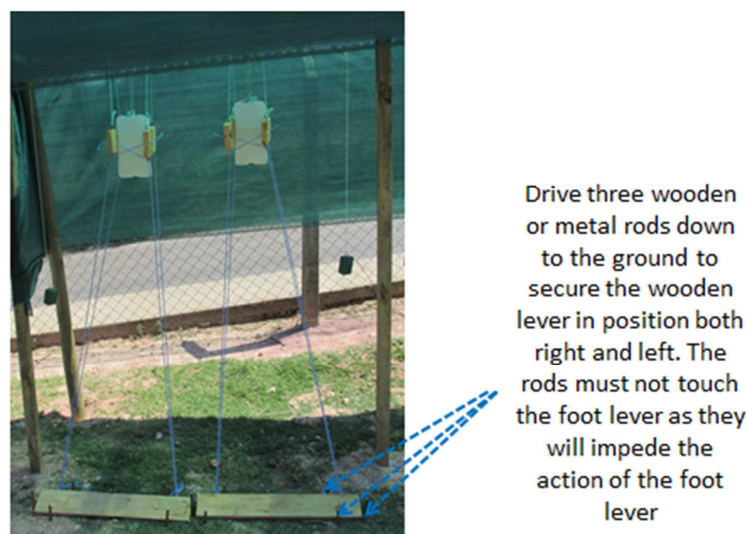

Figure 7. Securing the position of the foot lever through wooden or metal rods driven left and right of the foot lever in triangular fashion. 
The wooden flaps are typically sized to be $10 \mathrm{~cm}$ by $25 \mathrm{~cm}$ (Figure 8). They are provided to the right and left of the water holding container. The ropes are tied to the wooden flaps from the top end and extended through wire rings that are secured to holes drilled at the bottom of the wooden flaps. However, the wire rings may not be necessary as some of the constructed facilities allow the rope to pass through holes drilled at the bottom of the wooden flaps.

The wooden flaps should gently hold the container and should only be allowed to be pressed towards each other when force is exerted on the foot lever (Figure 9). The positions of the wooden flaps, therefore, should be located properly with respect to the water holding container that is hanged from the top.
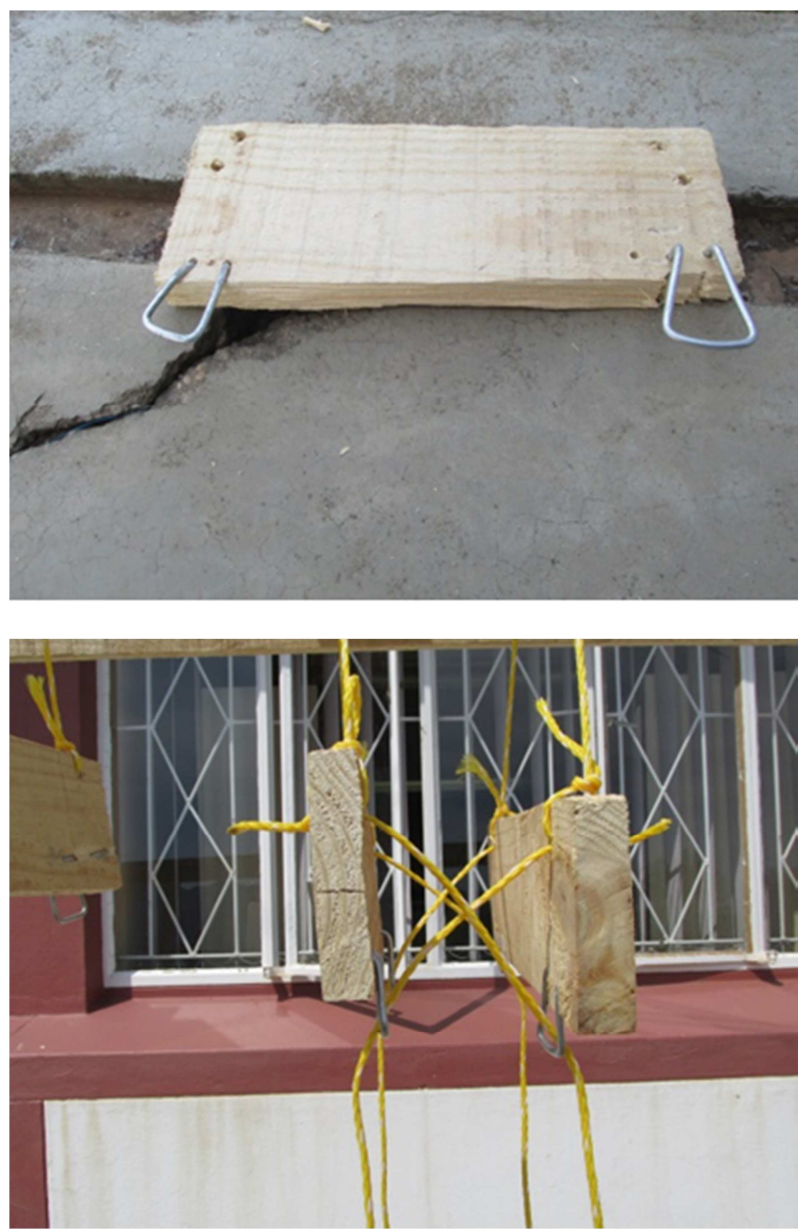

Figure 8. Construction of wooden flaps with tension ropes for transmitting pressing force to water holding container.

The water holding container which is made of plastics is hanged from the top through ropes tied to the handle at the top of the container (Figure 10). A small hole is drilled at the bottom of the container. If larger volume of water is desired multiple small holes can be drilled at the bottom of the water holding container to increase the water supply during hand washing. Since plastic material can be damaged and crack when exposed to sun ray over a longer period of time, it is recommended that the plastic container be shaded from the effect of the sun to increase its life span.

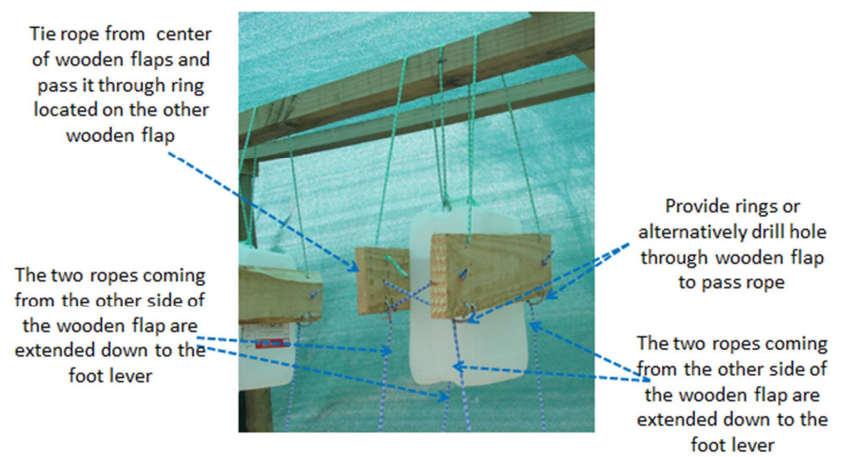

Figure 9. Positioning of the wooden flaps with ropes and water holding container.

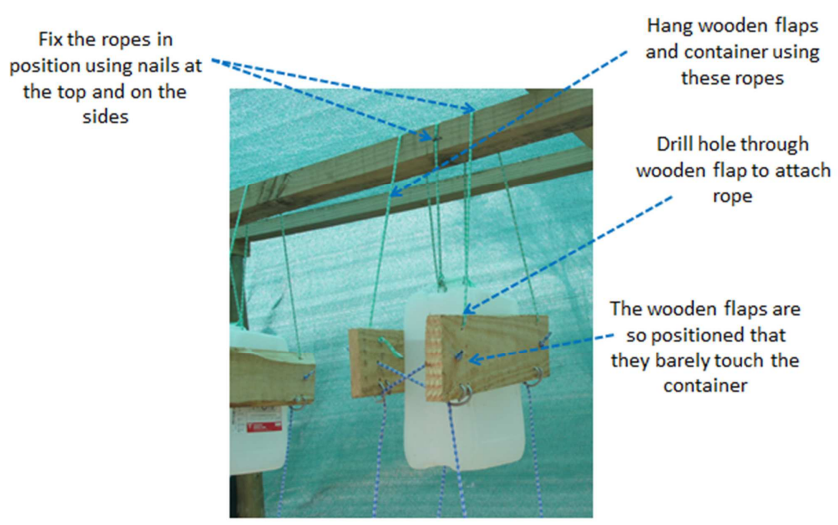

Figure 10. Connection of water holding container on frame and arrangement of wooden flaps on the left and right side.

The complete construction of a demonstration Press tap hand washing facility is shown in Figure 11. The frame should be secured into the ground and provision for drainage such as infiltration holes filled with permeable material can be provided in order to receive and drain away the used wash water at the ground below the press tap containers. Alternatively the used water can be treated and reused such as for gardening.

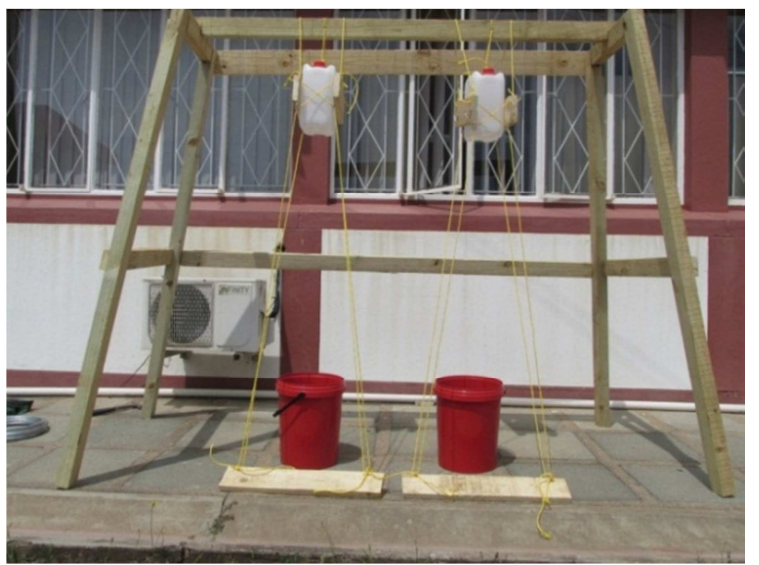

Figure 11. Construction of the complete Press Tap hand washing setup.

\subsection{Provision for Soap Washing}

The Press Tap hand washing facility can be combined with provision for soap using the same principle of press tapping. 
An illustration of a soap provision is shown in Figure 12. In this arrangement a smaller volume plastic bottle (1 -2 liters) is used and is hanged from the top. The press tapping arrangement is likewise extended to this soap bottle. The soap liquid should be diluted appropriately to conserve the soap use. In order to conserve soap, the drilled hole at the bottom of the soap holding bottle should have very small size. Where solid soap is being used, a string can be tied to the soap and the string hanged from the top of the frame. This type of soap provision is also shown in Figure 12.
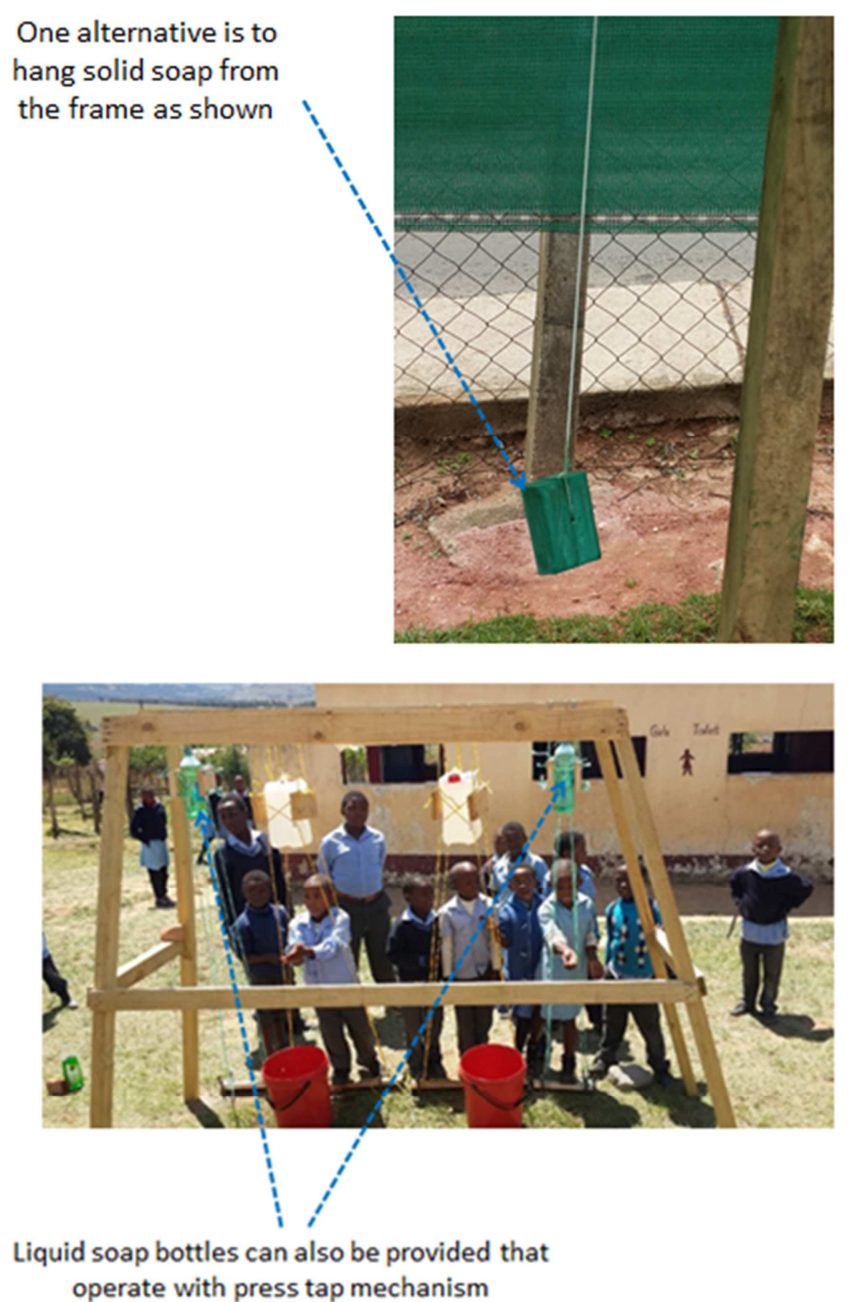

Figure 12. Alternative provision for soap: Solid soap tied with string from the supporting frame and liquid soap that operated on the same principle of a Press Tap.

\subsection{Operational Aspects}

Initial pilot trials were carried out by providing the Press tap hand washing facilities at The Church of Christ in Mnyamatsini, at the New Hebron School and at the children care point center in Mangwaneni, Swaziland. The pilot trials enabled successful modification to be made to the initial proposals. For example the size of the foot lever was reduced. The rounded nails that were used for connecting the ropes were discarded as they detach easily and were replaced with strong wires and later on holes in the woods requiring no wire. The position of the foot lever had also to be secured with driven wooden pegs as erratic movement of the foot lever by children can lead to rope breakage. In addition, optimum position of the foot lever is required always to ensure that water does not splash on foot (when the foot lever is too near the container) or there is difficulty in reaching the dripping water by hand (when the foot lever is too far away from the container). Provision of shelter for the water holding container was also critical as it was found out that some of the plastic containers that were directly exposed to the sun cracked after prolonged exposure to sun ray. Container materials that are not strong were observed to shrink and deform as water continues to flow out of the container due to the increasing pressure difference between the inside and outside walls of the container. It is, therefore, essential that reasonably strong plastic containers be used for holding water. Such containers are often not difficult to find in the local markets. It may also be helpful to provide round shaped container rather than square ones as they tend to shrink and deform less compared to the square shaped water holding containers.

Education and training of the users is important in order to ensure that the Press Tap hand washing facility is used properly. Some users who are unaware of the mode of operation can inappropriately tamper with the container such as by trying to open the top cap which leads to water wastage and contamination. Children might also try to play with the device or spend too much time on the hand wash and need to be educated and regulated in this regard. A caretaker should be appointed where the facility is provided as group hand washing facility with the required training on operation and maintenance aspects.

Normally a small volume of water of up to about $50 \mathrm{~mL}$ is adequate for hand washing and the device conserves water very well. If greater volume of water is required, as explained earlier it is easy to accommodate this by drilling more small holes at the bottom or by increasing the size of a single hole. In this case, greater volume of water flows out per a given time during hand washing. However, there is a tradeoff as the water may be exhausted quicker. Figures 13-16 show the Press Tap hand washing facilities installed at various locations as initial pilot trials.

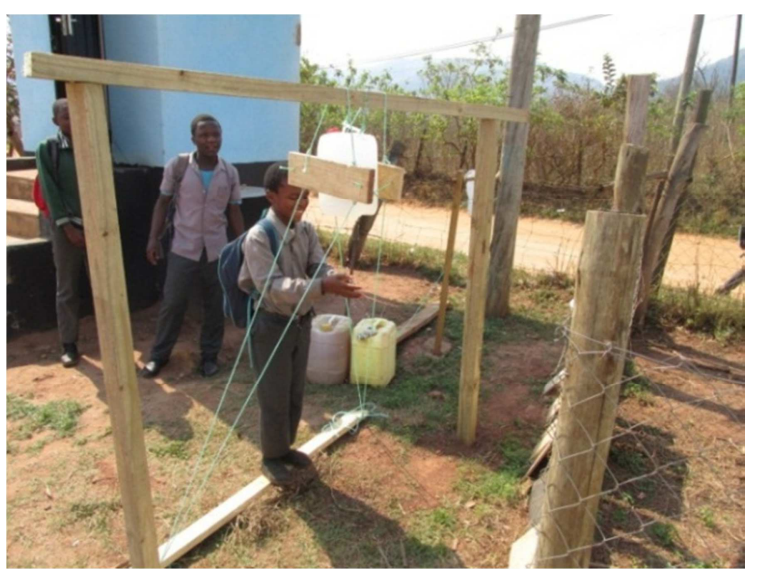

Figure 13. Press tap hand washing provide at the Church of Christ, Mnyamatsini. 


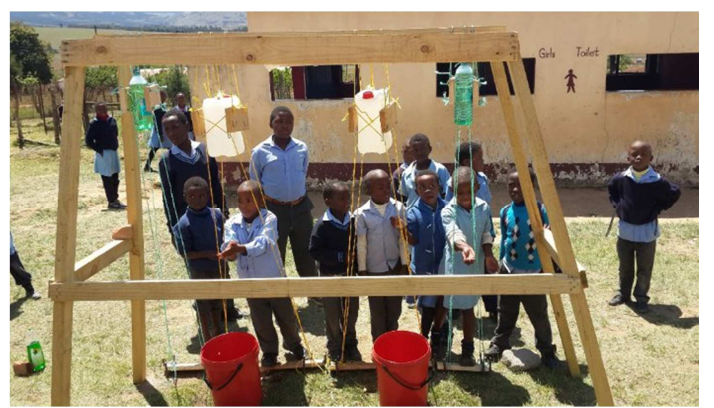

Figure 14. Press tap hand washing facility provided at the New Hebron School.

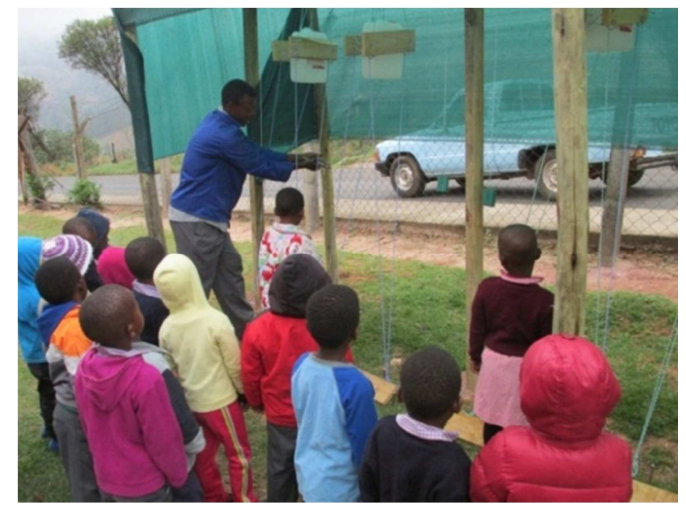

Figure 15. Press Tap hand washing demonstration for children in Mangwaneni, Swaziland.

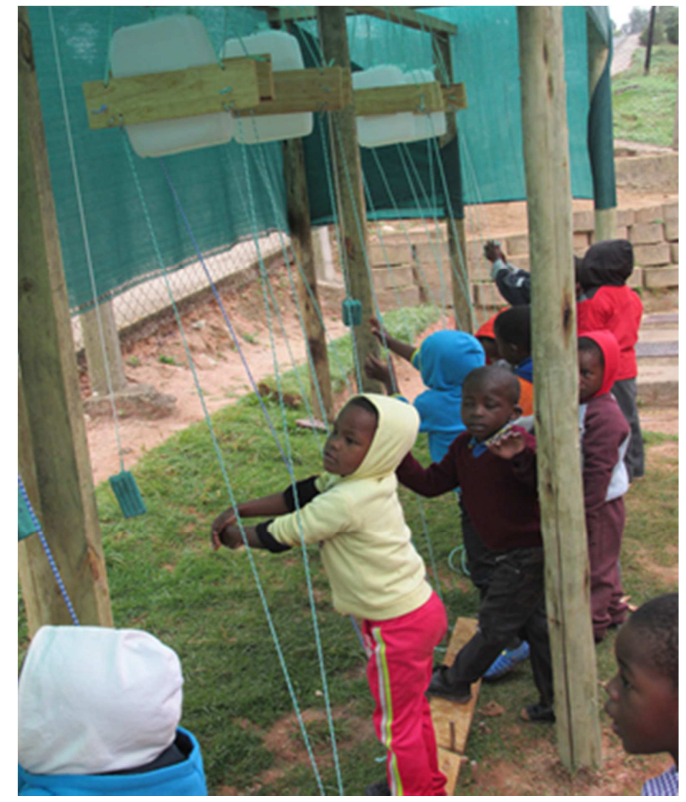

Figure 16. Children practicing Press Tap hand wash at Mangwaneni care point center.

\section{Conclusion}

The development of Press Tap hand washing facility has been shown to be an important addition to existing technologies for hand washing where piped water supply are not available and hand washing is a strong intervention for breaking the cycle of transmission of many water borne and water washed diseases. The Press Tap hand washing facility is shown to be easy to construct and operate requiring the usage of simple, low cost and locally available materials.

The conceptual development of the Press Tap hand washing facility is based on a sound scientific basis and its validity is, therefore, assured in any geographical and user settings. The operation of the hand washing facility through a force exerted on a foot lever makes the device hygienic since the hand is not involved in opening and closing a tap, a practice that is so common in conventional and washing facilities but something that is unhygienic. Compared to the tippy tap, this hand washing device has a stable operation as the water holding container merely presses instead of tipping. In addition the foot lever is connected through more secure multiple ropes and requires little force to operate the device. This means that children can comfortably stand on the press tap and easily manage to wash their hands. This has been demonstrated in the various pilot trials that were conducted with the Press Tap hand washing facility at a number of locations in Swaziland. It is also possible to combine the hand washing facility with soap use. A liquid soap that operates with the same principle of Press Tap has been demonstrated to work and is thus a hygienic alternative as the foot rather than the hand is being used to squeeze soap out of the soap containing bottle. It is also often observed that provision of powder and liquid soap in user friendly manner is not necessarily simple.

The use of Press Tap hand washing facility is observed to conserve water as washing can be practice with less amount of ware dropping from the container. With the use of $50 \mathrm{~mL}$ of water per hand wash, a 6 liter capacity water holding container can enable washing of about 120 people. If more water is required for washing it is easy to adapt the device to this requirement by opening several small holes at the bottom of the water holding container. The facility requires periodic filling and before equilibrium is attained leading to water stoppage, a water loss of about $50 \mathrm{~mL}$ per 6 liter container occurs. This loss through the bottom hole can be conserved by collecting the water droppings during the stage water is dripping after willing of the container.

The Press Tap hand washing facility can be installed in different user settings including provision as group hand washing facility. In order to prolong the life of the plastic containers, shading of the facility is helpful. Training and awareness creation are important in order to ensure that the facility is used properly. Where the facility is provided as group hand washing facility such as in schools, it is essential to appoint a caretaker with the required training in operation and maintenance to ensure that the facilities are being taken care of and that water is always available for hand washing.

\section{Acknowledgment}

This research study was supported by the government of Finland as part of the Mbabane Dry Sanitation and Waste Management Project (MDSWMP) research activity. The researchers would like to thank the financial assistance provided for carrying out the research work. 


\section{References}

[1] Walker CLF, Rudan I, Liu L, Nair H, Theodoratou E, Bhutta ZA, O'Brien KL, Campbell H, Black RE (2013). Global burden of childhood pneumonia and diarrhea. Lancet., 381 (9875): 1405-1416.

[2] Cairncross S, Hunt C, Boisson S, Bostoen K, Curtis V, Fung IC, Schmidt W-P (2010). Water, sanitation and hygiene for the prevention of diarrhea. Int J Epidemiol., 39: 1193-1205.

[3] Aiello AECRM, Perez V, Larson EL (2008). Effect of Hand Hygiene on Infectious Disease Risk in the Community Setting: A Meta-Analysis. Am J Public Health, 98 (8): 1372-1381.

[4] Global Public-Private Partnership for Hand washing (2015). Accessed on May 21, 2016 from: http://globalhandwashing.org/

[5] Devine J (2009). Introducing SaniFOAM: A Framework to Analyze Sanitation Behaviors to Design Effective Sanitation Programs, in Water and Sanitation Program: Working Paper, Washington DC: World Bank, Water and Sanitation Program.

[6] Hulland KRS, Elli Leontsini E, Dreibelbis R, Unicomb L, Afroz, A, Dutta NC, Nizamme FA, Luby SP, Ram PK and Winch PJ (2013). Designing a hand washing station for infrastructure-restricted communities in Bangladesh using the integrated behavioral model for water, sanitation and hygiene interventions (IBM-WASH). BMC Public Health BMC series, 13:877.

[7] Devine J (2010). Beyond tippy-taps: The role of enabling products in scaling up and sustaining hand washing. Waterlines Vol. 29 No. 4.

[8] Kane, M. (2009) Rapport Etude Lavage des Mains Au Savon Senegal, unpublished study, Water and Sanitation Program, World Bank, Washington, DC.

[9] Delisio, K. (2009) Behavioral Determinants of Hand washing among Peruvian Caregivers: Analysis of Baseline Data from The Water and Sanitation Program (WSP)'s Scaling Up Hand washing Behavior Change Initiative (Master's Thesis, John Hopkins University).

[10] Luby, S., Halder, A., Tronchet, C., Akhter, S., Bhuiya, A. and Johnson, R. (2009) 'Household characteristics associated with hand washing with soap in rural Bangladesh', American Journal of Tropical Medicine and Hygiene 81: 882-7.

[11] Scott, B., Curtis, V., Rabie, T. and Garbrah-Aidoo, N. (2007) 'Health in our hands but not in our heads: Understanding hygiene motivation in Ghana', Health Policy and Planning 22: 225-33.

[12] Cairncross, S., Shordt, K., Zacharia, S. and Kumari Govindan, B. (2005) 'What causes sustainable changes in hygiene behavior? A cross-sectional study from Kerala India', Social Science and Medicine 61: 2212-20.

[13] USAID (2015). Use of Tippy Taps and Hand washing Practices in Southern Bangladesh. JSI Research \& Training Institute, Inc. Arlington, VA 22209 USA.

[14] Curtis VA, Danquah LO, Aunger RV (2009). Planned, motivated and habitual hygiene behavior: an eleven country review. Health Educ Res., 24 (4): 655-673.

[15] Fisher J (2008). Women in water supply, sanitation and hygiene programmes. Proc ICE Munic Eng., 161 (4): 223-229.

[16] Chapin, J. (2009) Designing a Hand washing Station for Rural Vietnamese Households, presentation, Water and Sanitation Program, World Bank, Washington, DC.

[17] Watt, J. (1988). The Tippy Tap: A simple hand washing device for rural areas. Journal of Tropical Pediatrics 34: 91-92.

[18] Naughton CC (2013). Assessing Appropriate Technology Hand washing Stations in Mali, West Africa. M. Sc. thesis, University of South Florida.

[19] Biran, A (2011). Enabling technologies for hand washing with soap: A case study on the Tippy-Tap in Uganda." Global Scaling Up Hand washing Project Water and Sanitation Program.

[20] Sreenivasan N, Gotestrand SA, Ombeki S, Oluoch G, Fischer TK, Quick R. (2015). Evaluation of the impact of a simple hand-washing and water-treatment intervention in rural health facilities on hygiene knowledge and reported behaviors of health workers and their clients, Nyanza Province, Kenya, 2008. Epidemiol Infect, 143(4): 873-80.

[21] Bennett SD, Otieno R, Ayers TL, Odhiambo A, Faith SH, Quick R (2015) Acceptability and use of portable drinking water and hand washing stations in health care facilities and their impact on patient hygiene practices, Western Kenya. PLoS ONE.:10(5): e0126916.

[22] Christensen G, Dentz HN, Pickering AJ, Bourdier T, Arnold BF, Colford JM Jr, Null C.(2015) Pilot cluster randomized controlled trials to evaluate adoption of water, sanitation, and hygiene interventions and their combination in rural western Kenya. Am J Trop Med Hyg. 92(2): 437-47.

[23] Contzen N, Meili IH, Mosler HJ (2015). Changing hand washing behavior in southern Ethiopia: A longitudinal study on infrastructural and commitment interventions. Social Science \& Medicine, 124: 103-14.

[24] Mbuya MN, Tavengwa NV, Stoltzfus RJ, Curtis V, Pelto GH, Ntozini R, Kambarami RA, Fundira D, Malaba TR, Maunze D, Morgan P, Mangwadu G, Humphrey JH (2015) Sanitation Hygiene Infant Nutrition Efficacy (SHINE) Trial Team. Design of an Intervention to Minimize Ingestion of Fecal Microbes by Young Children in Rural Zimbabwe. Clin Infect Dis., 61(7): S703-709.

[25] Harris Interactive (2010). Survey of hand washing behavior. Retrieved from http://www.microbeworld.org/images/stories/washup/2010_ha ndwashing_behavior.survey.pdf. 